\title{
Intra-specific morphological plasticity in three Puntius species in Sri Lanka
}

\author{
M.P.K.S.K. de Silva, N.P.P. Liyanage \\ Department of Zoology, University of Ruhuna, Matara, Sri Lanka, kumududs@zoo.ruh.ac.lk
}

S. Hettiarachi

Department of Botany, University of Ruhuna, Matara, Sri Lanka

\begin{abstract}
Phenotype of an organism is a result of interaction of genotype and environment. Individuals of a same species living in variety of habitats may subject to different environmental conditions. As a result, they may adapt to local conditions in those habitats which include the changes in morphology from the common phenotype. Different morphologies in individuals of same genotype is called phenotypic plasticity. This is considered as an important event in evolutionary ecology because these individuals are the first to subject to natural selection. Present study focused on phenotypic plasticity in three freshwater fish species namely Puntius dorsalis, $P$. vitatus and $P$. bimaculatus. Fish were sampled from different locations in four different altitude ranges of five major rivers of Sri Lanka. Twenty three length measurements and fifteen meristic characters were recorded from each individual and fourteen physicochemical parameters of each location were also measured. Relationship between altitude range and the species morphology was analysed by discriminant analysis and hierachical cluster analysis. Correlation of physicochemical parameters with the altitude range was also studied. Results showed that individuals living in different altitude ranges in different rivers and also in the same river were morphologically different. Results indicated that length characters which determine the shape of the individual mainly contribute to the discrimination of individuals according to their respective altitude range. Ratios of maximum body width to standard length, pre ventral length to post ventral length and fork length to standard length in P. dorsalis, $P$. vitatus and P. bimaculatus respectively were the main discrimination characters that grouped the individuals according to the respective altitudes. Variations in length characters were found to be adaptations to their habitat.

Most physicochemical parameters were significantly correlated (negatively or positively) according to the altitude ranges where three species were collected. Phenotypic plasticity in the three Puntius species inhabiting different altitudes may have resulted as an adaptation to these variable physicochemical parameters.
\end{abstract}

Key words: morphological plasticity, intra-specific, altitude, Puntius

\section{Introduction}

Phenotypic plasticity is the ability of a genotype to respond to alternative environmental conditions to produce array of phenotypes (Thompson 1991). In forming a phenotype, the genome and the environment act on the developmental programme (Scheiner 1993). Genetic variation in a fixed phenotype has been hypothesized to be favored in stable environments (Smith 1993) whereas phenotypic plasticity can be an important adaptive strategy for coping with environmental variability (Scheiner 
1993), predation (Abrams 2003), for differences in availability of resources such as food (Lindsay 1981, Magnan 1988) and habitat choice of individuals (Smith and Sikulason 1996).

Aquatic environments exhibit great spatial and temporal variability in both abiotic and biotic habitat parameters (Lowe-McConnell 1987, Goulding et al. 1988) and intraspecific diversification is well documented in fishes (Robinson \& Wilson 1994, Smith \& Skúlason 1996, Taylor 1999, Jonsson \& Jonsson 2001). Adaptive phenotypic plasticity in fish morphology has been demonstrated in crucian carp, Carassius carassius, in response to the presence or absence of a predator (Brönmark \& Miner 1992), and in pumpkinseed sunfish, Lepomis gibbosus (Robinson \& Wilson 1996) and stickleback, Gasterosteus spp. (Day et al. 1994), in response to differences between benthic and pelagic habitats.

In Chum salmon (Oncorhynchus keta), variation in morphometric and meristic characters according to different temperature conditions in water has been recorded (Beacham 1990). Body shape in fishes has been demonstrated to be influenced by type of food or feeding mode (Day et al.1994, Robinson \& Wilson 1996). Barbus neumayeri living in hypoxic habitats (swamps) has shown larger gill size compared to those living in streams which have better oxygen supply (Chapman et al. 1999, Chapman and Liem 1995). Body shape of the hatchery reared and wild Atlantic salmon also tend to be heavily influenced by rearing conditions (von Cramon et al. 2005).

Divergence of structure, behaviour or habitat could support more living beings to live in the same area. Individual phenotypic differences are important in understanding the evolutionary ecology of a population or a species because variation among individuals is the raw material on which natural selections first acts on. Phenotypic variation in a species could lead to genotypic variation and this could even lead to origin of a species in long term.

Puntius is a Genus of freshwater fish belonging to Family Cyprinidae. There are 16 Puntius species in Sri Lanka. They inhabit in a variety of aquatic environments; i.e., rivers, streams, reservoirs, or tanks; waters of stagnant, slow flowing or with strong currents; deep or shallow; relatively higher to lower altitudes and clear or turbid waters (Schut et al.1984). Three commonly found indigenous Puntius species, namely $P$. bimaculatus, $P$. dorsalis and $P$. vitatus were considered in the present study.

According to Schut et. al. 1984, P. bimaculatus adults were mainly found in hill country in small and large streams while juveniles were found in marshes. In contrast, $P$. vitatus found in marshes and paddy lands with turbid water in lowlands. $P$. dorsalis has the widest range of distribution from the rocky hill streams to main rivers below flood level and also found in tanks and reservoirs.

These three species show three types of distribution (hill country, lowlands and wide range), where environmental factors (soils, water bodies and altitude ranges) are different. Body shape (morphology) of these fish could be adapted to suit these differing environmental conditions. 
Table 1 Altitude ranges where sampling done in five Rivers.

\begin{tabular}{|c|c|c|c|c|c|}
\hline $\mathrm{P}_{\text {River }}$ Altitude & Mahaweli & Kalu & Kelani & Nilwala & Gin \\
\hline $0-150$ & 0 & $\circ \square \triangle^{*}$ & $\circ \square \triangle^{*}$ & $\circ \square \triangle^{*}$ & $\mathrm{O} \square$ \\
\hline $150-300$ & $\circ \triangle$ & $\circ$ & ○ & & $\square$ \\
\hline $300-600$ & $\circ \triangle$ & ○ & $\triangle$ & $\triangle$ & \\
\hline $600-1200$ & $\triangle$ & & $\circ$ & & $\triangle$ \\
\hline $1200-1800$ & $\triangle^{*}$ & & & & \\
\hline
\end{tabular}

$\circ$ P. dorsalis $\square$ P. vitatus $\triangle$ P. bimaculatus

${ }^{*}$ Not used in the analysis as the samples were not in suitable condition to take measurements.

Objective of the present study was to determine whether variability of macrohabitats, mainly altitude and the type of water body, has any effect on morphological plasticity of these three Puntius spp. in five major rivers namely Mahaweli, Kelani, Kalu, Nilwala and Gin.

\section{Materials and Methods}

Five major rivers Mahaweli, Kalu, Kelani, Gin and Nilwala were selected for the study. Sampling was carried out in five different altitude ranges of each river. Fish samples were collected using hand nets, scoop nets, cast nets and gape nets from streams, streamlets, rivulets and reservoirs belonging to five river basins. Figure 1 shows the sampling sites and Table 1 shows the altitude range of which the species were caught in each location. Total number of fish collected was 31, 53 and 43 for $P$. vitatus, $P$. bimaculatus and $P$. dorsalis, respectively. In each altitude range more than one location was sampled. Other fish species caught were released back to the water and three Puntius spp. used for the study were preserved in $70 \%$ alcohol and brought to the laboratory. Species of the fish were identified according to their external morphology and 23 length measurements (measurables) and 15 meristic characters (countables) were recorded from each fish. List 1 shows the characters recorded.

Fourteen physicochemical parameters of water; temperature, pH, alkalinity, salinity, conductivity, dissolved oxygen, suspended organic matter, suspended inorganic matter, organic suspended solids, chlorophyl content, chemical oxygen demand, biological oxygen demand, phosphate levels and nitrate levels were measured at the sampled sites using standard methods. 
De Silva, Liyanage and Hettiarachchi: Intra-specific Morphology ...

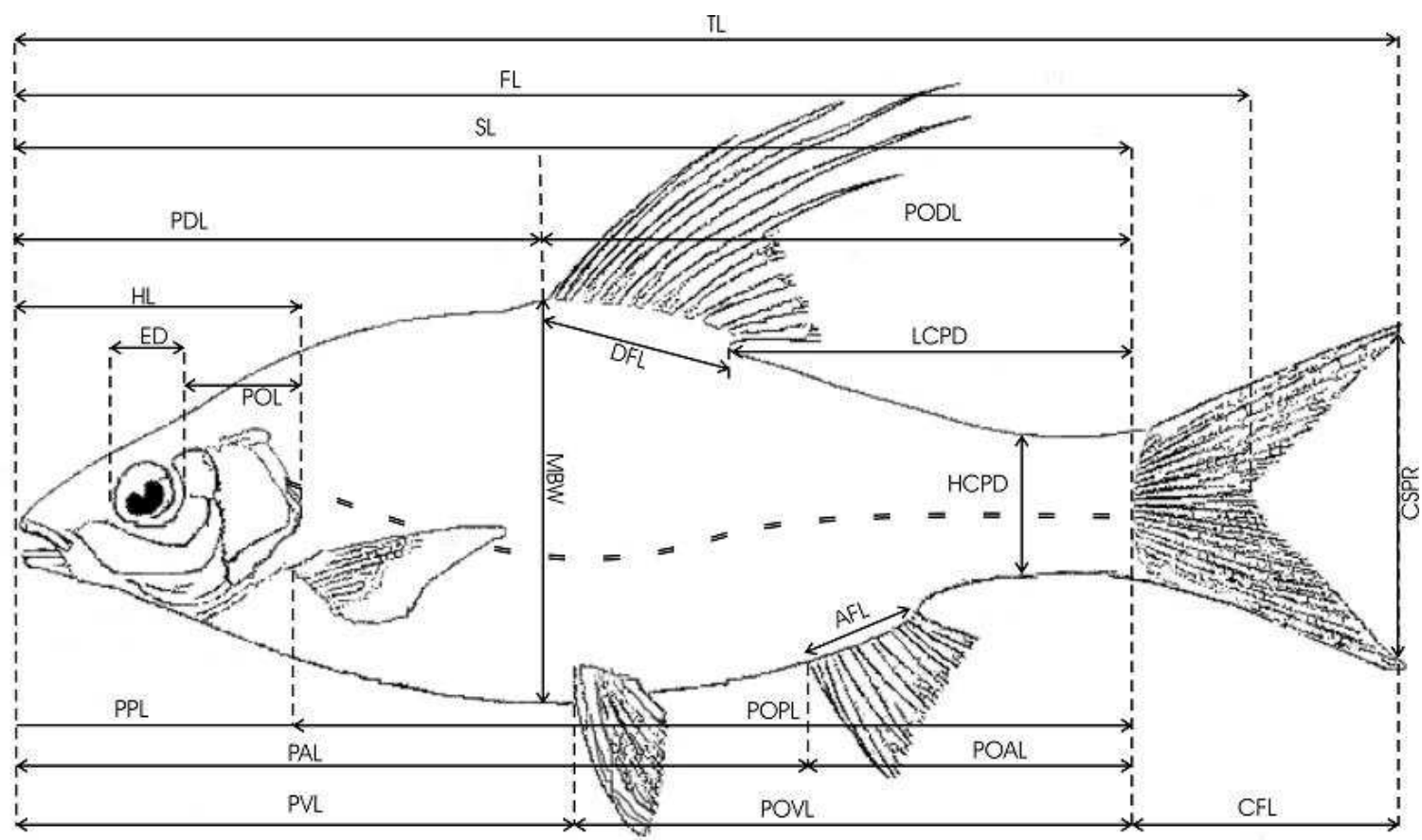

Figure 1 Length measurements recorded

Note. (abbreviations are defined in List 1)

List 1 Morphometric and meristic characters used

(a) Morphometric characters

TL - Total length

MBW - Maximum Body Width

POL - Post orbital length

SL - Standard length

PDL - Pre dorsal length

AFL - Anal fin length

POAL - Post anal length

POVL - Post ventral length

POPL - Post pectoral length

CSPR - Caudal spread

HCPD - Least depth of caudal peduncle

IND - Inter nostril distance
FL - Fork length

HL - Head length

DFL - Dorsal fin length

ED - Eye diameter

PODL - Post dorsal length

PAL - Pre anal length

PVL - Pre ventral length

PPL - Pre pectoral length

CFL - Caudal fin length

LCPD - Length of caudal peduncle

IOW - Inter orbital width

LLS - No. of lateral line scales 
(b) Meristic characters

TR - No. of transverse scales CPED - Scales around caudal peduncle

DFR - Dorsal fin rays

DFS - Dorsal fin spines

VFR - Ventral fin rays

VFS - Ventral fin spines

PFR - Pectoral fin rays

PFS - Pectoral fin spines

AFR - Anal fin rays

AFS - Anal fin spines

PRDS - Pre dorsal fin scales

PSDS - Post dorsal fin scales

CFR - Caudal fin rays

DFSC - Dorsal fin scales

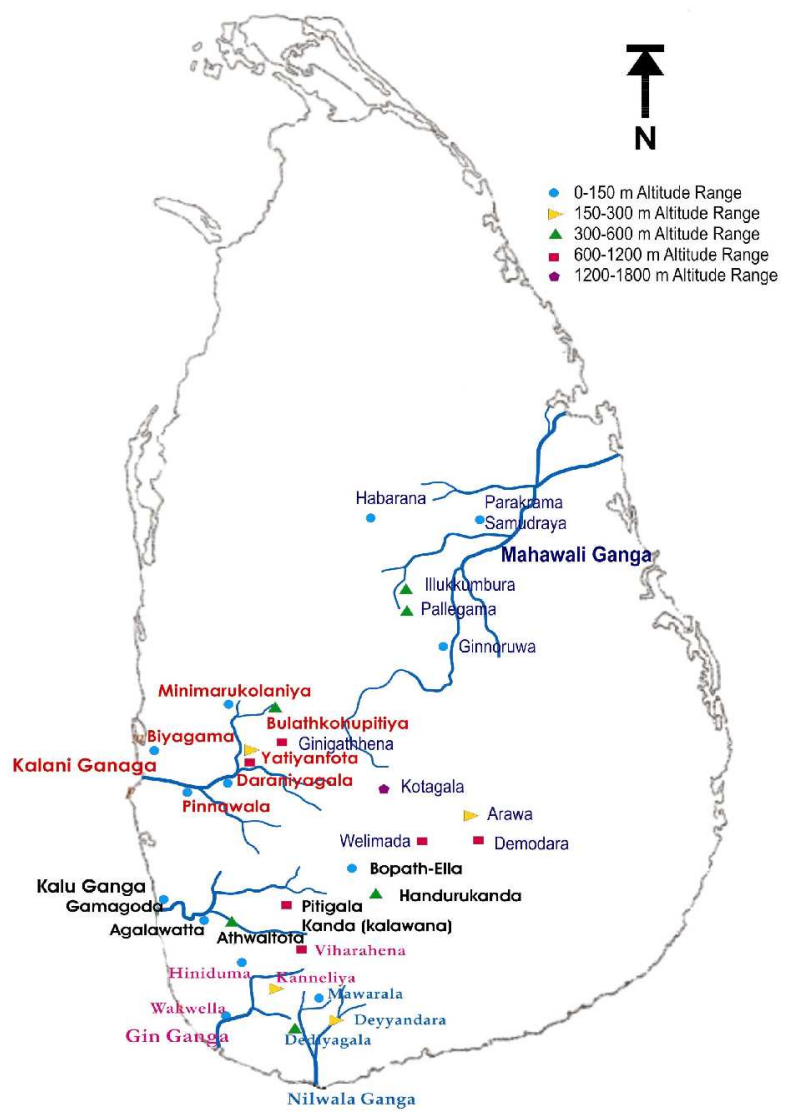

Figure 2 Rivers and sampling sites

Note. ${ }^{*}$ Locations in five rivers are shown in five different fonts

As the fish were in different sizes, length measurements were converted to ratios to standerdise for the size of the fish. Analysis was carried out for each species separately. Size adjusted length ratios and meristic characters were subjected to discriminant function analysis using step wise insertion of variables to find out the canonical functions, characters that contribute for the highest percentage variance and principal components that contribute to discriminate the species according to 
Table 2 No. of functions, percentage variance and the characters that contribute for the discrimination of the individuals to their respective altitude range

\begin{tabular}{|l|l|l|l|l|l|l|l|l|}
\hline \multicolumn{3}{|c|}{ P. dorsalis } & \multicolumn{3}{c|}{ P. vitatus } & \multicolumn{3}{c|}{ P. bimaculatus } \\
\hline $\begin{array}{l}\text { Function } \\
\text { No. }\end{array}$ & $\begin{array}{l}\% \\
\text { variance }\end{array}$ & Character & $\begin{array}{l}\text { Function } \\
\text { No. }\end{array}$ & $\begin{array}{l}\% \\
\text { variance }\end{array}$ & Character & $\begin{array}{l}\text { Function } \\
\text { No. }\end{array}$ & $\begin{array}{l}\% \\
\text { variance }\end{array}$ & Character \\
\hline 1 & 74.2 & MBW.TL & 1 & 100 & PVL.POVL & 1 & 83.8 & FL.SL \\
2 & 22.5 & POAL.SL & & & & 2 & 16.2 & POL.SL \\
3 & 3.4 & POVL.SL & & & & & & \\
\hline
\end{tabular}

the altitude range that they were found. Mean plots were obtained for the major characters that contribute for the highest percentage variance for the altitudinal ranges. Principal components obtained were used to cluster the fish according to the altitudes by hierachical cluster analysis. SPSS 10 statistical package was used for the analysis.

Physicochemical parameters were log transformed. Relationship between physicochemical parameters and altitude ranges were analysed by correlation analysis to determine the most variable parameters in the four altitude ranges in five rivers.

\section{Results}

Results of the canonical discriminant analysis show that from the 39 morphological descriptors (24 length ratios and 15 meristic), length ratios mainly contribute to the discrimination of individuals (Table 2). In P. vitatus ratio of pre ventral length and post ventral length contribute totally for discrimination (100\%). Fork length mainly contributes to discriminate $P$. bimaculatus (83.8\%). As the percentage variance for post anal length and post ventral length is low, maximum body depth is the major discriminating factor for $P$. dorsalis.

Mean plots obtained by one way ANOVA for these characters show that body width (MBW.SL) is significantly higher in the $P$. dorsalis individuals in lowest altitude of 0-150 m (Figure 3a). In P. vitatus mean PVL.POVL is highest in 0-150 $\mathrm{m}$ altitude range shows that ventral fin is positioned more posteriorly (Figure $3 \mathrm{~b}$ ). High mean values obtained for the fork length in $P$. bimaculatus collected from high altitudes (600-1200 m) show that they have longer caudal fins. For the individuals living in lower altitudes high mean value was obtained for the post orbital length indicate that they have longer heads (Figure 3 (c) and (d)). Six, five and seven principal components were obtained for $P$. dorsalis, $P$. vitatus and $P$. bimaculatus, respectively. Both meristic and length measurements were contributed to group the individuals of $P$. bimaculatus, $P$. dorsalis and $P$. vitatus according to the altitudinal ranges. Except for three cases for each species, in $P$. vitatus and $P$. bimaculatus all the individuals belonging to the same altitude in different rivers were grouped together. Grouping of individuals in $P$. dorsalis did not strictly follow that pattern.

Figures 4, 5, and 6 show the clustering of individuals of three species according to the altitude ranges. $P$. vitatus was found only from samples collected at lower altitudes (0-150 $\mathrm{m}$ and 150-300 $\mathrm{m}$ ) and they form two distinct clusters at $20 \%$ level in the dendrogram (1A and 1B) representing two altitudes (Figure 4). Individuals of 


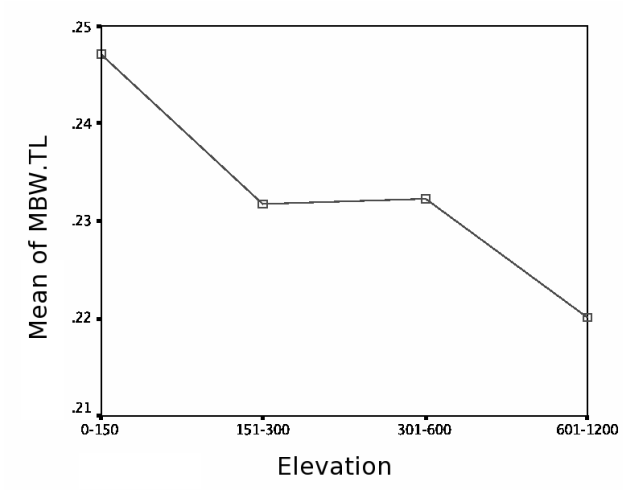

(a)P. dorsalis

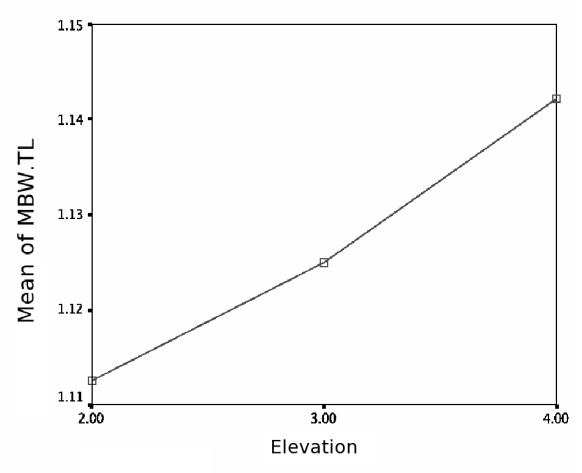

(c) P. bimaculatus

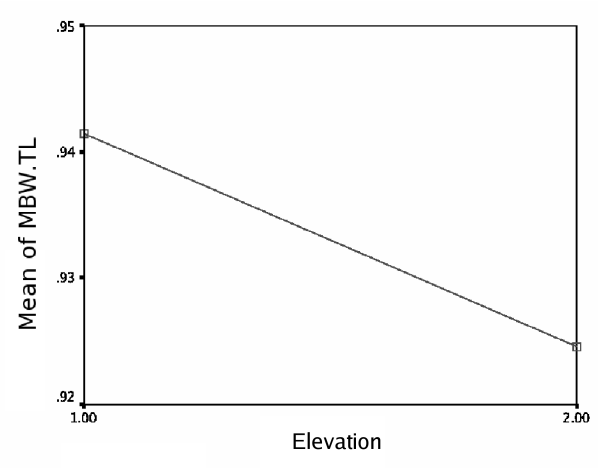

(b) P.vitatus

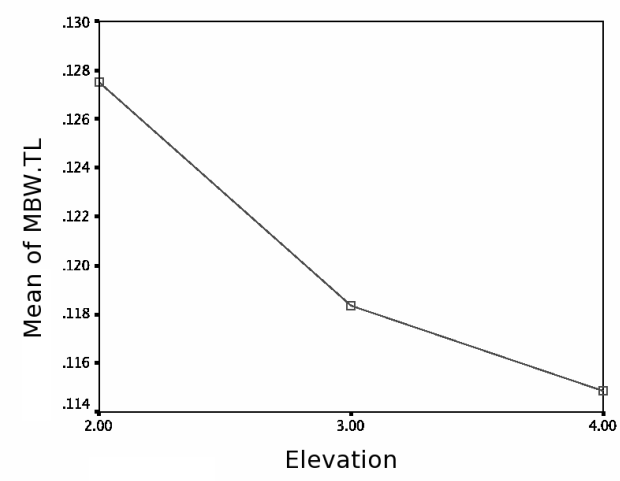

(d) P. bimaculatus

Figure 3 Mean plots showing the variation of the main discriminant characters according to the altitude range for 3a. P. dorsalis, 3b. P.vitatus and 3c. P. bimaculatus

Table 3 Key morphometric characters extracted for three Puntius species

\begin{tabular}{|l|l|l|}
\hline \multicolumn{3}{|c|}{ Principal components } \\
\hline P. dorsalis $^{*}$ & P. vitatus & P. bimaculatus \\
\hline MBW.SL $^{*}$ & PVI.POVL $^{*}$ & FL.SL \\
POAL.SL $^{*}$ & POVL.SL & POL.SL * \\
POVL.SL & POL.POPL & PODL. SL \\
TR & CFL.CSPR & LLS \\
CFR & DFR & AFR \\
PRDS & & PFR \\
& & CFR \\
\hline
\end{tabular}

* Principal components that give highest percentage variance for the canonical functions

P. bimaculatus of Nilwala River collected from 300-600 m altitude range separated out first at $80 \%$ level in the dendrogram (1A1 and 1A2 of Figure 5). From the rest, individuals of altitude 150-300 m clustered separately from individuals of altitude range 600-1200 m (2A1 and 2A2).Compared with the other two species $P$. dorsalis 


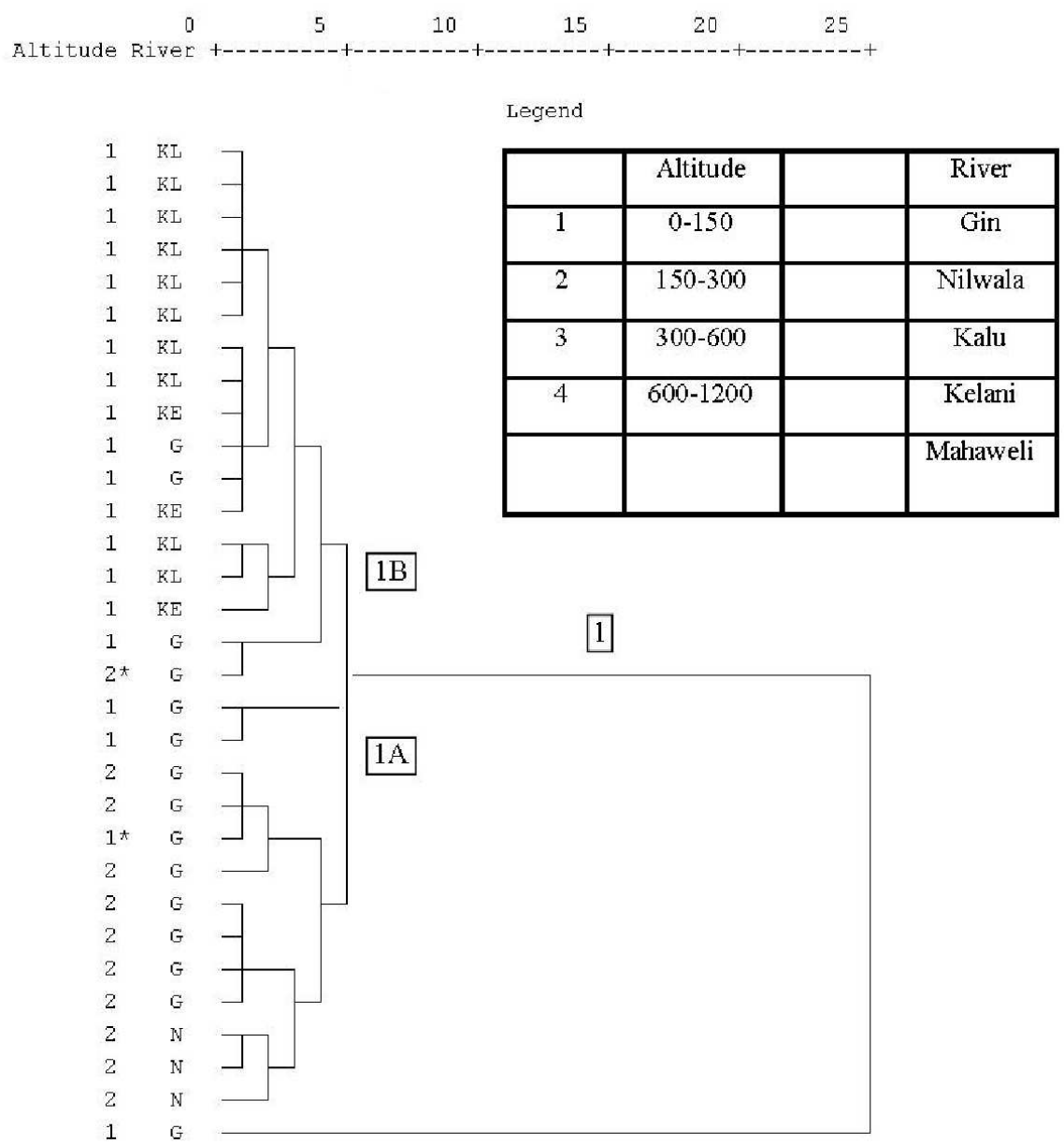

Figure 4 Clustering of $P$. vitatus according to the altitudes

Note. ${ }^{*}$ misclassified cases

does not show distinct separation in morphology according to the altitude ranges. Individuals belonging to $150-300 \mathrm{~m}$ range in Nilwala River (1A) show different morphology from the rest of $P$. dorsalis individuals and individuals belonging to other three altitude ranges do not show much difference in their morphology (Figure $6)$.

Correlation analysis of altitude range and physicochemical parameters of the localities where three species were collected show that most characters are negatively correlated with the altitude. Results of the same analysis for P. bimaculatus show some positively correlated parameters (Table 4). Chlorophyll content in the water shows no significant correlation with the altitude. 


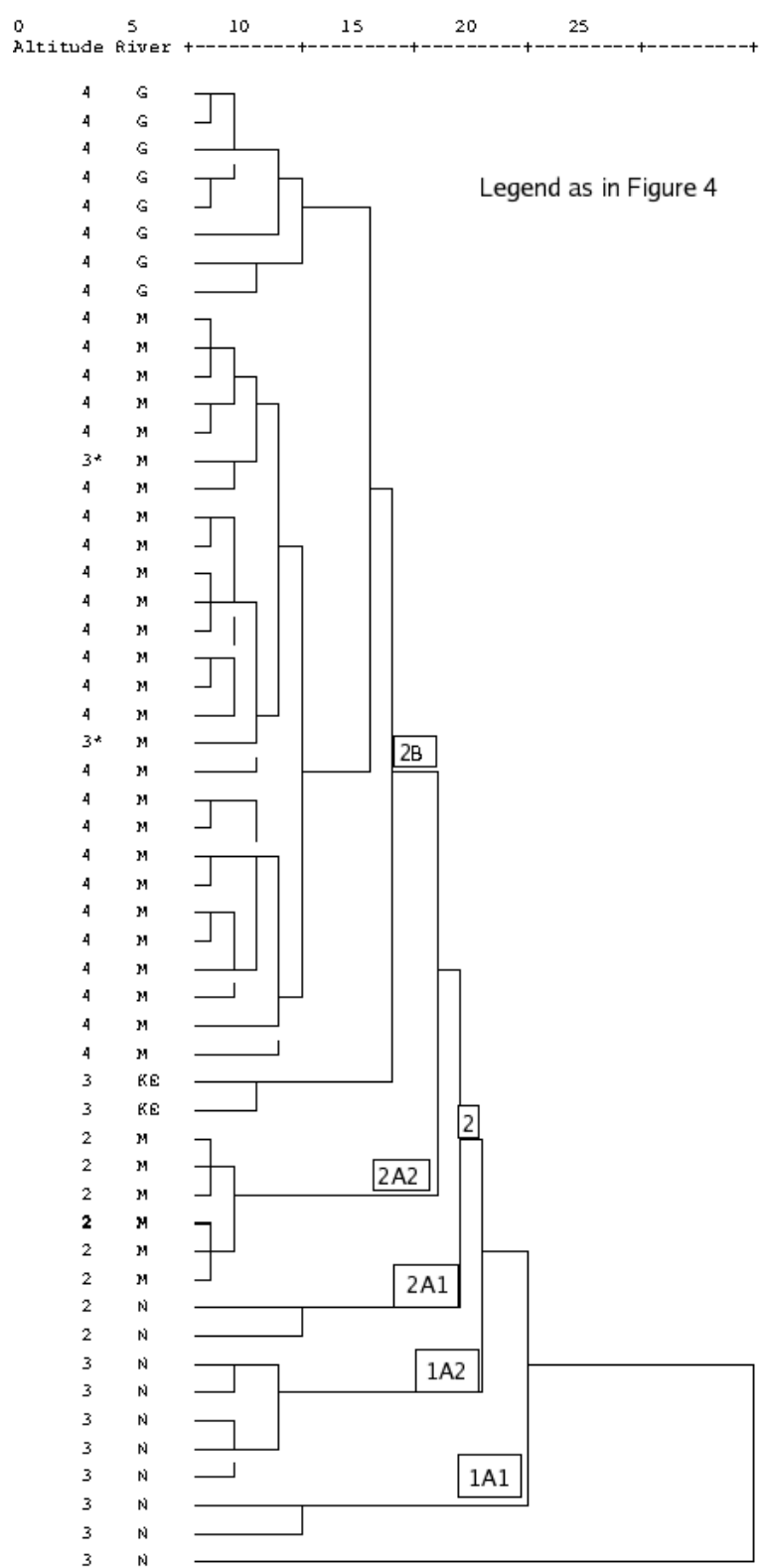

Figure 5 Clustering of $P$. bimaculatus according to the altitudes Note. ${ }^{*}$ misclassified cases

\section{Discussion}

According to principal component analysis positioning of fins in the body is important in discriminating the individuals of $P$. vitatus in relation to the two altitudinal ranges in which they were found. Position of the ventral fin, which contributes to $100 \%$ variance for canonical functions and the pectoral fin, is more anteriorly placed in individuals collected from the lowest altitude range $(0-150 \mathrm{~m})$. $P$. vitatus is mainly 
De Silva, Liyanage and Hettiarachchi: Intra-specific Morphology ...

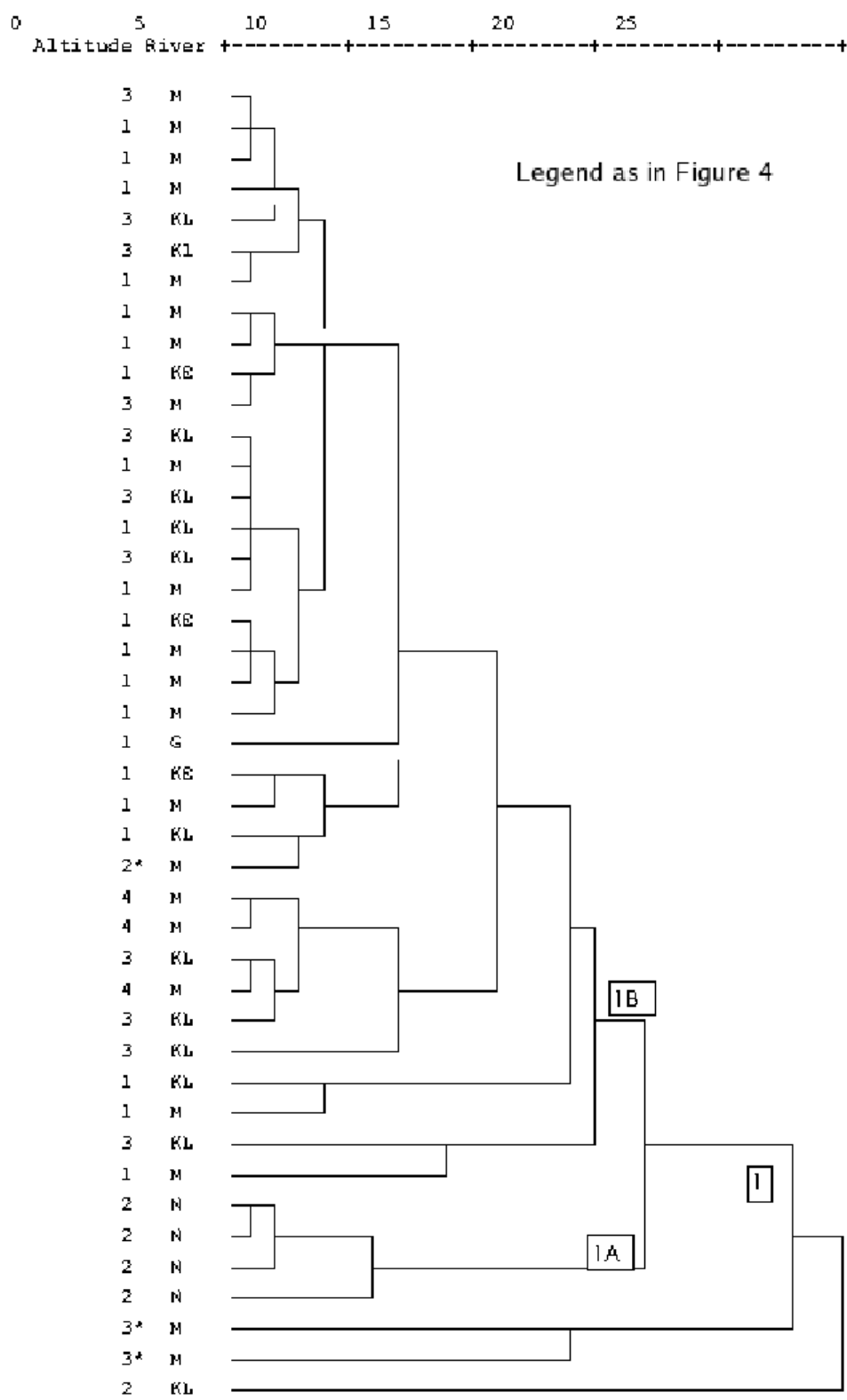

Figure 6 Clustering of $P$. dorsalis according to the altitudes.

Note. ${ }^{*}$ misclassified cases

found in marshes and paddy fields. In paddy fields, large numbers of this species gather under spillways and other places with flowing water (Schut et al.1984). More anteriorly placed lateral fins are an adaptation for living in streams (Brinsmead and Fox, 2003). Individuals collected from altitude range of 150-300 $\mathrm{m}$ have larger caudal spread and this is also an adaptation to their habitats such as spillways with arduous environmental conditions. 
Table 4 Significant correlations obtained for altitude ranges and physicochemical parameters of the locations where three species collected

\begin{tabular}{|l|l|l|}
\hline P. dorsalis & P. vitatus & P. bimaculatus \\
\hline - Temperature & - Conductivity & - Temperature \\
- pH & - Total suspended solids & - Dissolved oxygen \\
- Conductivity & - Organic suspended solids & - Biological oxygen demand \\
- Total suspended solids & - Inorganic suspended solids & + Chemical oxygen demand \\
- Organic suspended solids & - Biological oxygen demand & + Salinity \\
- Inorganic suspended solids & - Salinity & + Phosphate \\
- Biological oxygen demand & - Nitrate & \\
- Chemical oxygen demand & + Dissolved oxygen & \\
- Salinity & & \\
- Alkalinity & & \\
- Nitrate & & \\
- Phosphate & & \\
\hline
\end{tabular}

- negative correlation, + positive correlation

P. bimaculatus is found in the rocky hill streams (Schut et al. 1984). This was the only Puntius species found in highest altitude studied (Table 1). Morphological characters that contributed most to the canonical function analysis in $P$. bimaculatus are related to caudal fin length and head length. Comparison of mean plots of these characters for lower altitudes and higher altitudes showed that individuals in high altitudes have long bodies with longer caudal fins and shorter head lengths. Habitats of $P$. bimaculatus individuals found in higher altitudes are in steep hills with fast flowing waters. As such water in those habitats gets well aerated. Longer caudal fins give them more fusiform bodies so that they can withstand fast flowing water. Longer post orbital lengths in individuals in lower altitudes is an adaptation to provide more space to increase the size of the gill (Lindsay 1981) possibly through increasing the number of gill filaments. Garra ceylonensis which is highly adapted to fast flowing water, was the only other Cyprinid species found in the highest altitudes, in addition to $P$. bimacualtus.

$P$. dorsalis was found in most of the locations sampled and had the widest distribution. Individuals living in the lowest altitudes have deeper bodies and their lateral fins are placed more anteriorly than those in higher altitudes. Webb and Wehis (1986) have shown that these characters are the optimal design for maneuvering type of locomotion. $P$. dorsalis is commonly found in reservoirs and tanks too. Deep body is also an adaptation to live in littoral habitats (Robinson et al. 1996).

Principal components obtained for each Puntius species were able to classify the individuals according to the altitude ranges they were collected. Individuals sampled from the same altitude range of different rivers clustered together indicating that altitude has considerable effect on the morphology of the species. Except for a few individuals, phenotypically similar individuals of different rivers belonging to a same altitude could be grouped together. It would be interesting to study this relationship with different fish genera to generalise this outcome. 
Individuals that develop and mature in common environmental conditions may share a similar phenotype. When the movement between riverine populations is limited they develop population specific phenotypes (Jerry and Cairns 1998). Present demonstration of significant similarities found in most physicochemical parameters of the same altitude range in different rivers may have created common environmental influences. This may have caused the individuals to be shaped into similar phenotypes in the same species in those environments. Barlow (1961) has shown that latitudinal changes in temperature have affected the expression of morphological characters. Similarly the differences found in some physicochemical parameters among altitude ranges may have resulted in differences in phenotype of the same species shown in present study. More experimental work are required to further describe the role that ecological conditions play in maintaining morphological diversity in these groups.

$P$. dorsalis being a macrophagous herbivore and the other two species being algae and diatom feeders their distribution may depend on the availability of their food source. However chlorophyll content of water shows no significant correlation among altitudes. Therefore any correlation between chlorophyll content and morphology of Puntius cannot be demonstrated.

Many organisms can modulate their morphology in response to environmental cues. Such plasticity is thought to be an important adaptive strategy for populations experiencing variable environmental conditions (Scheiner 1993) and it is likely that phenotypic plasticity plays an important role in diversification (West-Eberhard 1989).

Morphology in teleost fish has been shown to be particularly labile in response to multifarious habitat effects (Kinsey et al. 1994, Corti et al. 1996). Present study also shows that the morphology of a species in the same river but different localities could differ. This may lead to form in different populations as the movement of individuals among the most localities is difficult. These populations subject to local selection pressures leading ultimately to increased fitness termed local adaptations (Carvalho 1993).This could even result genetic divergence of populations. Future studies on genetic component of these phenotypes would result a better picture of phenotypic plasticity of Puntius species.

\section{References}

Abrams PA. 2003. Can adaptive evolution or behaviour lead to diversification of traits determining a trade-off between foraging gain and predation risk? Evolutionary Ecology Research 5:653-670

Beacham TD. 1990. A genetic analysis of meristic and morphometric variation in chum salmon (Oncorhynchus keta) at three different temperatures. Canadian Journal of Zoology 68: 225-229

Barlow GW. 1961. Causes and significance of morphological variation in fishes. Systematic Zoology 10: 105-117 
Brinsmead J and Fox MG. 2003. Morphological variation between lake- and streamdwelling rock bass and pumpkinseed populations. Journal of Fish Biology 61:16191638

Brönmark C. and Miner JG. 1992. Predator-induced phenotypical change in body morphology in crucian carp. Science 258: 1348-1350

Carvalho GR. 1993. Evolutionary aspects of fish distribution: genetic variability and adaptation. Journal of Fish Biology 43 (Suppl A): 53-73

Chapman LJ., Chapman CA., Brazeau DA., McLaughlin B. and Jordan, M. 1999. Papyrus swamps, hypoxia and faunal diversification: variation among populations of Barbus neumayeri. Journal of Fish Biology 54:310-327

Chapman LJ. and Liem K.F. 1995. Papyrus swamps and the respiratory ecology of Barbus neumayeri. Environment and Biology of Fishes 44:183-197

Corti M., Loy A. and Cataudella S. 1996. Form changes in sea bass, Dicentrachus labrax (Moronidae: Teleostei), after acclimatation to freshwater: an analysis using shape coordinates. Enviornmental Biology of fishes 47: 165-175

Day T. and McPhail JD. 1996. The effect of behavioural and morphological plasticity on foraging efficiency in the three spine stickleback (Gasterosteus sp.). Oecologia 108:380-388

Day T. Pritchard J. and Schluter D. 1994. A comparison of two sticklebacks. Evolution 48:1723-1734

Goulding M., Carvalho ML. and Ferreira EG. 1988. Rio Negro: rich life in poor water. Hague, the Netherlands: SPB Academic Publishing.

Jerry DR. and Cairns SC. 1998. Morphological variability in the catadromous Australian bass, Macquaria novemaculeata (Perciformes: Percichthyidae), from seven geographically distinct riverine drainages. Journal of Fish Biology 52: 829-843

Jonsson B. and Jonsson N. 2001. Polymorphism and speciation in Arctic charr. Journal of Fish Biology 58:605-638

Kinsey ST., Orsoy T., Bert T.M. and Mahmoudi B. 1994. Population structure of the Spanish sardine Sardinella aurita: natural morphological variation in a genetically homogenous population. Marine Biology 118: 309-317

Lindsay CC. 1981. Stocks are chameleons: plasticity in gill rakers of Corrigonid fishes. Canadian Journal of Fisheries and Aquatic Sciences 38:1497-1506

Lowe-McConnell RH. 1987. Ecological Studies in Tropical Fish Communities. Cambridge: Cambridge University Press

Magnan P. 1988. Interactions between Brook charr, Salvelinus fontinalis, and nonsalmonid species: ecological shift, morphological shift, and their impact on zooplankton communities. Canadian Journal of Fisheries and Aquatic Science 45:9991009

Robinson BW. and Wilson DS. 1994. Character release and displacement in fishes: A neglected literature. American Naturalist 144:596-627 
Robinson BW. and Wilson DS. 1996. Genetic variation and phenotypic plasticity in a trophically polymorphic population of pumpkinseed sunfish (Lepomis gibbus). Evolutionary Ecology 10:631-652

Robinson BW, Wilson DS and Shea GO. 1996. Trade-offs of ecological specialization: an intraspecific comparison of pumpkinseed sunfish phenotypes. Ecology 77:170178

Scheiner SM. 1993. Genetics and evolution of phenotypic plasticity. Annual Review of Ecology and Systematics 24:35-68

Schut J,, De Silva S. and Kortmulder K. 1984. Habitat associations and competition of eight Barbus (=Puntius) species (Pisces, Cyprinidae) indigenous to Sri Lanka. 34(2):159-181

Smith TB. 1993. Disruptive selection and the genetic basis of bill size polymorphism in the African Finch Pyrenestes. Nature 363:618-620

Smith TB. and Sklason S. 1996. Evolutionary significance of resource polymorphism in fishes, amphibians and birds. Annual Review of Ecology and Systematics 27:111-133

Taylor EB. 1999. Species pairs of north temperature freshwater fishes: Evolution, taxonomy and conservation. Reviews in Fish Biology and Fisheries 9: 299-324.

Thompson JD. 1991. Phenotypic plasticity as a component of evolutionary change. Trends in Ecology and Evolution 6:246-249

Von Cramon T., Ling EN., Cotters D. and Wilkins NP. 2005. Determination of body shape variation in Irish hatchery-reared and wild Atlantic salmon. Journal of Fish Biology 66: 1471-1482

Webb PW. and Weihs D. 1986. Functional locomotor morphology of early life history stages of fishes. Transactions of the American Fisheries Society 115:115-127

West-Eberhard MJ. 1989. Phenotypic plasticity and the origins of diversity. Annual Review of Ecology and Systematics 20:249-278

\section{Acknowledgments}

Financial assistance provided by National Science Foundation of Sri Lanka under the research grant RG/BT/2003/02 is highly appreciated. 